\title{
Critically evaluated rate coefficients in radical polymerization -8 . Propagation rate coefficients for vinyl acetate in bulk
}

Christopher Barner-Kowollik, ${ }^{1}$ Sabine Beuermann, ${ }^{2}$ Michael Buback, ${ }^{3}$ Robin A. Hutchinson, ${ }^{4 *}$ Thomas Junkers, ${ }^{5}$ Hendrik Kattner, ${ }^{3}$ Bart Manders, ${ }^{6}$ Anatoly N. Nikitin, ${ }^{7}$ Gregory T. Russell, ${ }^{8}$ Alex M. van Herk ${ }^{9}$

1. Preparative Macromolecular Chemistry, Institut für Technische Chemie und Polymerchemie, Karlsruhe Institute of Technology (KIT), Engesserstraße 18, 76131 Karlsruhe, Germany and Institut für Biologische Grenzflächen, Karlsruhe Institute of Technology (KIT), Herrmann-vonHelmholtz-Platz 1, 76344 Eggenstein-Leopoldshafen, Germany.

2. Institute of Technical Chemistry, Clausthal University of Technology, Arnold-SommerfeldStraße 4, 38678 Clausthal-Zellerfeld, Germany

3. Technical and Macromolecular Chemistry Group, Institut für Physikalische Chemie, University of Göttingen, Tammannstraße 6, D-37077 Göttingen, Germany

4. Department of Chemical Engineering, Dupuis Hall, Queen's University, Kingston, Ontario K7L 3N6, Canada, E-mail: robin.hutchinson@queensu.ca

5. Polymer Reaction Design Group, Institute for Materials Research, Universiteit Hasselt, Martelarenlaan 42, BE-3500 Hasselt, Belgium.

6. BASF SE, EDG/DD - H503, 67056 Ludwigshafen am Rhein, Germany

7. Institute on Laser and Information Technologies - Branch of the Federal Scientific Research Centre "Crystallography and Photonics" of Russian Academy of Sciences, Svyatoozerskaya 1, Shatura, Moscow Region, 140700, Russia

8. Department of Chemistry, University of Canterbury, Private Bag 4800, Christchurch 8140, New Zealand

9. Eindhoven University of Technology, Dept Of Chemistry and Chemical Engineering, 5600 MB, PO Box 513, Eindhoven The Netherlands 


\section{Summary}

Propagation rate coefficients, $k_{\mathrm{p}}$, reported by several groups for radical polymerization of bulk vinyl acetate (VAc) are critically evaluated. All data were obtained by the combination of pulsed-laser polymerization (PLP) and subsequent polymer analysis by size exclusion chromatography (SEC), as recommended by the IUPAC Working Party on Modeling of Polymerization Kinetics and Processes. Although a small $(\sim 15 \%)$ increase in $k_{\mathrm{p}}$ is observed as laser pulse repetition rate is increased from low $(25-100 \mathrm{~Hz})$ to high $(300-500 \mathrm{~Hz})$ values, all of the data fulfill the required consistency criteria and thus are combined into a benchmark set covering the temperature range of 5 to $70{ }^{\circ} \mathrm{C}$. The data are fitted well by an Arrhenius relation resulting in a pre-exponential factor of $1.35 \times 10^{7} \mathrm{~L} \cdot \mathrm{mol}^{-1} \cdot \mathrm{s}^{-1}$ and an activation energy of 20.4 $\mathrm{kJ} \cdot \mathrm{mol}^{-1}$, with $95 \%$ confidence ellipsoids for the parameters also presented.

Keywords: radical polymerization, kinetics, vinyl acetate, pulsed laser polymerization 


\section{Introduction}

The development of the PLP-SEC method ${ }^{[1]}$ - pulsed-laser polymerization (PLP) combined with analysis of the chain-length distribution of the resulting polymer by size exclusion chromatography (SEC) - for determination of the propagation rate coefficient, $k_{\mathrm{p}}$, has been of utmost importance in the investigation of the kinetics of radical polymerization (RP). As a result, the reliability and accuracy in estimation of not only this parameter but also other rate coefficients - e.g. the termination rate coefficient, $k_{\mathrm{t}}^{[2]}-$ measured relative to it have been considerably improved. Therefore the IUPAC Subcommittee on Modeling of Polymerization Kinetics and Processes has recommended PLP-SEC as the method of choice for determining $k_{\mathrm{p}}{ }^{[3]}$

The PLP-SEC method evaluates the propagation rate coefficient using the following equation: ${ }^{[4]}$

$$
L_{i}=i k_{\mathrm{p}}[\mathrm{M}] t_{\mathrm{d}}
$$

Here $[\mathrm{M}]$ is the monomer concentration and $t_{\mathrm{d}}$ is the separation time between the periodic laser pulses. Each such pulse generates a fresh population of highly concentrated radicals, instantaneously (on the timescale of RP kinetic events) increasing the probability for terminating the radicals generated by the $i^{\text {th }}$ previous pulse, these having propagated up to average (and nearly monodisperse) chain length $L_{i}$ during the time interval $i \times t_{\mathrm{d}}$. This enhanced termination results in features - either peaks or distinct shoulders - in the molar-mass distribution (MMD) of the resulting (dead) polymer. Differentiation of the MMD highlights the location of these features: a point of inflection on the low-MM side of an MMD peak is a maximum in the derivative trace, while a peak is where the derivative trace crosses the chain-length axis. It is found that the maxima from the derivative plot generally provide the best estimate of $k_{\mathrm{p}}$ using Equation (1). ${ }^{[3]}$ This is because although pulsing instantaneously generates radicals to enhance the rate of termination, the termination itself is not instantaneous but instead plays out over a 
period of time that is small but non-negligible in comparison with $t_{\mathrm{d}}$. Thus it is the low-MM inflection of each peak or shoulder that best corresponds to average growth length between pulses. ${ }^{[1]}$ Ordinarily the first peak in the MMD, generated by termination between radicals from successive pulses, is the most pronounced such that the first point of inflection $\left(L_{1}\right)$ is most reliably located and should be used in Equation (1) for determination of $k_{\mathrm{p} .}{ }^{[3]}$

In addition to simplicity, the PLP-SEC method provides self-consistency criteria for reliable $k_{\mathrm{p}}$ estimation. The main criterion is the occurrence of a secondary inflection point located at twice the chain length of the first inflection point: $L_{2} \approx 2 L_{1}$, with higher inflection points also seen for some systems. ${ }^{[1],[3]}$ Further consistency criteria are the independence of the obtained $k_{\mathrm{p}}$ on initiator concentration, laser power, and pulse repetition rate (prr). ${ }^{[3]}$

By now the PLP-SEC method has been applied to a multitude of monomers, enabling a series of benchmark papers ${ }^{[3],[5]-[10]}$ reporting accurate Arrhenius parameters for $k_{\mathrm{p}}$ of a significant range of monomers. While the established consistency criteria have been fulfilled relatively easily for bulk styrene ${ }^{[3]}$ and methacrylate ${ }^{[5]-[7]}$ systems, difficulties have arisen for acrylates. Namely, poly(alkyl acrylate) MMDs generated at $100 \mathrm{~Hz}$ or lower and at temperatures above about $20^{\circ} \mathrm{C}$ have shown at best a broadened PLP structure, and at worst no PLP structure at all. This has resulted in poor estimates of $k_{\mathrm{p}}$, as evidenced by deviation from Arrhenius behavior (above about $20^{\circ} \mathrm{C}$ ) when measured at pulse repetition rates of $100 \mathrm{~Hz}$ or lower. ${ }^{[8],[10]}$

After about a decade of investigation, consensus emerged that intramolecular chain transfer to polymer - commonly known as 'backbiting' - is the reason behind this behavior of acrylates. ${ }^{[8],[10],[11]}$ This reaction results in the formation of so-called mid-chain radicals (MCRs), which are more stable than chain-end radicals (CERs), and thus exhibit considerably lower propagation activity. In terms of PLP, this has two consequences. The first is that formation of MCRs destroys the linear relationship between reaction time and average (radical) chain length: when a subsequent pulse arrives, radicals that have undergone backbiting will be smaller than those that have not, thus creating a broadened MMD. ${ }^{[8],[10]}$ The second effect is that the average 
chain length grown between pulses is an average over both the MCR and CER populations, and thus the 'effective' $k_{\mathrm{p}}$ is lower than that for CERs. The issue here is that any factor that influences the balance between MCRs and CERs will change the effective $k_{\mathrm{p}}$. For example, because backbiting has a considerably higher activation energy than CER propagation, increasing the temperature increases the frequency of backbiting relative to chain-end growth, and thus the effective $k_{\mathrm{p}}$ is lowered relative to CER $k_{\mathrm{p}}$, explaining non-Arrhenius behavior above $20{ }^{\circ} \mathrm{C}$. Similarly, increasing the pulse repetition rate acts to decrease the time between pulses, meaning that fewer MCRs are created on the PLP timescale. Thus the effective $k_{\mathrm{p}}$ is closer in value to the CER $k_{\mathrm{p}}$. In practical terms it has been found that pulse repetition rates above $100 \mathrm{~Hz}$ are generally sufficient to give negligible backbiting between pulses, resulting in successful PLP experiments that deliver $k_{\mathrm{p}}$ estimates that may be taken as CER values. Pulsing rates of $500 \mathrm{~Hz}$ are now routinely used to overcome the complication of backbiting in PLP of acrylates up to temperatures of $70{ }^{\circ} \mathrm{C} \cdot{ }^{[10],[12]}$

Much as with the acrylates, the first applications of the PLP-SEC method to (bulk) vinyl acetate (VAc) had only limited success. ${ }^{[13]-[15]}$ It was not possible to determine $k_{\mathrm{p}}$ at temperatures above $25^{\circ} \mathrm{C}$ at a pulse repetition rate of $10 \mathrm{~Hz}$, as the PLP-generated MMDs were broadened and featureless. ${ }^{[14]}$ Only a drastic decrease in radical concentration, e.g. decreasing benzoin concentration from 5.0 to $0.2 \mathrm{mmol} \cdot \mathrm{L}^{-1}$ at a given laser pulse energy, resulted in the emergence of PLP structure. ${ }^{[14]}$ The application of lasers that achieve higher repetition rates has led to further studies of VAc propagation by multiple research groups,${ }^{[16]-[20]}$ expanding the available results over a broader temperature range such that it is now possible to compile a benchmark data set for this industrially-relevant system. The benchmark data set is presented in Section 2, followed by discussion in Section 3 of a relatively small $(\sim 15 \%)$ but systematic increase seen in the measured $k_{\mathrm{p}}$ values as prr is increased from 50 to $500 \mathrm{~Hz}{ }^{[17],[19]}$ 


\section{Results}

The available experimental data from six different groups have been combined into a benchmark set for $k_{\mathrm{p}}$ of bulk VAc. As discussed in previous benchmark papers, the uncertainty associated with individual measurements is dependent on both PLP and SEC conditions, but can be considered to be on the order of $10 \%$, provided proper procedures are followed. ${ }^{[3],[5]}$ The individual experimental values collected in Table 1 all meet the IUPAC consistency criteria, and were obtained over a range of conditions, as detailed below. The data are combined and ordered according to temperature, with other pertinent experimental details - pulse repetition rate (prr), average laser-pulse energy $\left(E_{\mathrm{p}}\right)$, and photoinitiator type and concentration ([I]). It is noted that the critically evaluated data set of Table 1 is the largest yet assembled for a single monomer, with the following groups providing these data:

a) Hutchinson, Beuermann, and co-workers (DuPont laboratories). ${ }^{[14],[15]}$ The $k_{\mathrm{p}}$ values obtained by using low photoinitiator concentrations with prr of $10 \mathrm{~Hz}^{[14]}$ have been carefully reconsidered in a subsequent publication; ${ }^{[15]}$ in addition, application of a new laser operable up to a prr of $100 \mathrm{~Hz}$ resulted in MMDs with improved PLP structure. A total of 21 data points collected at varying prr $(25-100 \mathrm{~Hz})$ and laser power $(1.5-25 \mathrm{~mJ} /$ pulse $)$ covered the temperature range of $10-60{ }^{\circ} \mathrm{C}$ using benzoin as initiator at a concentration of $1 \mathrm{mmol} \cdot \mathrm{L}^{-1}$. As part of the investigation, Mark-Houwink-Kuhn-Sakurada (MHKS) parameters were determined as $K=$ $15.6 \times 10^{-5} \mathrm{dL} \cdot \mathrm{g}^{-1}$ and $a=0.708$ using triple-detector SEC analysis. ${ }^{[15]}$ These values, used by the other groups contributing benchmark values to the combined data set (Table 1), have subsequently been validated both by triple-detector SEC and by comparing to output from a light-scattering detector. ${ }^{[19],[21]}$

b) Manders and van Herk (Eindhoven laboratories). ${ }^{[16]}$ Experiments have been performed in bulk over the temperature range of 9.4 to $55.5^{\circ} \mathrm{C}$ with $1 \mathrm{mmol} \cdot \mathrm{L}^{-1}$ of 2,2 - 
dimethoxy-2-phenylacetophenone (DMPA) combined with a laser pulse energy of $40 \mathrm{~mJ}$, or with $0.4 \mathrm{mmol} \cdot \mathrm{L}^{-1}$ of photoinitiator in combination with a pulse energy of $30 \mathrm{~mJ}$. Pulse repetition rates have been chosen to be 50,75 and $100 \mathrm{~Hz}$.

c) Barner-Kowollik, Junkers and co-workers (Karlsruhe laboratories). ${ }^{[17]}$ Two series of experiments were carried out with $5 \mathrm{mmol} \cdot \mathrm{L}^{-1}$ of DMPA using a laser with energy of 1.5 $\mathrm{mJ} \cdot$ pulse $^{-1}$. The experiments of the first series were conducted at prr of 100, 150, 250 and 500 $\mathrm{Hz}$ at a temperature of $40.5^{\circ} \mathrm{C}$. The second series of experiments were carried out at $500 \mathrm{~Hz}$ over the temperature range of 4.7 to $70.2^{\circ} \mathrm{C}$.

d) Buback and Kattner (Göttingen laboratories). ${ }^{[18]}$ A series of experiments were carried out at $40.5^{\circ} \mathrm{C}$ and varying prr $(100,200,300$ and $400 \mathrm{~Hz})$ with $90 \mathrm{mmol} \cdot \mathrm{L}^{-1}$ dicumyl peroxide (DCP) used as photoinitiator at a laser pulse energy density of $2.63 \mathrm{~mJ} \cdot \mathrm{cm}^{-2}$. A second series of experiments were run at prr of 50,100 , and $400 \mathrm{~Hz}$ also at $40.5^{\circ} \mathrm{C}$, but with a lower pulse energy density of $0.86 \mathrm{~mJ} \cdot \mathrm{cm}^{-2}$. A final series of experiments was carried out at $400 \mathrm{~Hz}$ over the temperature range of 10 to $60{ }^{\circ} \mathrm{C}$ at constant pulse energy density $\left(0.86 \mathrm{~mJ} \cdot \mathrm{cm}^{-2}\right)$.

e) Hutchinson et al. (Kingston laboratories). ${ }^{[19]}$ The group has used the PLP-SEC method to investigate VAc polymerization over a range of 25 to $65{ }^{\circ} \mathrm{C}$, with experiments conducted at prr of $100,200,300,400$, and $500 \mathrm{~Hz}$ at each temperature and laser pulse energy in the range of 3.5 to $5.3 \mathrm{~mJ}$. While most work was conducted using benzoin photoinitiator at $5 \mathrm{mmol} \cdot \mathrm{L}^{-1}$, DMPA $\left(5 \mathrm{mmol} \cdot \mathrm{L}^{-1}\right)$ and DCP $\left(90 \mathrm{mmol} \cdot \mathrm{L}^{-1}\right)$ were also used at 30 and $50{ }^{\circ} \mathrm{C}$ to confirm that the prr dependence of $k_{\mathrm{p}}$ is independent of initiator type. For some experiments at 50 and $65{ }^{\circ} \mathrm{C}$, the MMD was analyzed using both light scattering and refractive index detectors; the resulting $k_{\mathrm{p}}$ estimates were in good agreement, with the average of the two values reported in Table 1. 
f) Beuermann et al. (Potsdam laboratories). ${ }^{[20]}$ The PLP-SEC method has been applied by this group for estimation of $k_{\mathrm{p}}$ for VAc polymerization over a range of 14.1 to $61.2{ }^{\circ} \mathrm{C}$, with 32 experiments conducted at prr of 50 and $100 \mathrm{~Hz}$ and with a laser pulse energy of $2 \mathrm{~mJ}$. Benzoin (0.9-1.2 $\left.\mathrm{mmol} \cdot \mathrm{L}^{-1}\right)$ and 2-methyl-4'-(methylthio)-2-morpholinopropiophenone (MMMP, $1.0 \mathrm{mmol} \cdot \mathrm{L}^{-1}$ ) were used as photoinitiators.

Table 1. Critically evaluated values of propagation rate coefficient, $k_{\mathrm{p}}$, for bulk vinyl acetate polymerization at ambient pressure measured as a function of temperature, $\Theta$, laser pulse repetition rate, prr, average laser-pulse energy, $E_{\mathrm{p}}$, initiator type and concentration, [I] ${ }^{a}$

\begin{tabular}{|c|c|c|c|c|c|c|}
\hline$\Theta /{ }^{\circ} \mathrm{C}$ & $\mathrm{prr} / \mathrm{Hz}$ & $E_{\mathrm{p}} / \mathrm{mJ}$ & Initiator & {$[\mathrm{I}] / \mathrm{mmol} \cdot \mathrm{L}^{-1}$} & $k_{\mathrm{p}} / \mathrm{L} \cdot \mathrm{mol}^{-1} \cdot \mathrm{s}^{-1}$ & Ref. \\
\hline 4.7 & 500 & 1.5 & DMPA & 5 & 2180 & [17] \\
\hline 4.7 & 500 & 1.5 & DMPA & 5 & 2080 & [17] \\
\hline 9.4 & 50 & 40 & DMPA & 1 & 1990 & [16] \\
\hline 9.4 & 50 & 40 & DMPA & 1 & 1930 & [16] \\
\hline 10 & $25-100$ & & Benzoin & & 2224 & [15] \\
\hline 10 & $25-100$ & & Benzoin & & 2242 & [15] \\
\hline 10 & $25-100$ & & Benzoin & & 2310 & [15] \\
\hline 10 & $25-100$ & & Benzoin & & 2345 & [15] \\
\hline 10 & $25-100$ & & Benzoin & & 2364 & [15] \\
\hline 10 & $25-100$ & & Benzoin & & 2502 & {$[15]$} \\
\hline 10 & $25-100$ & & Benzoin & & 2566 & [15] \\
\hline 10 & 400 & 0.86 & $\mathrm{DCP}$ & 90 & 2794 & {$[18]$} \\
\hline 10 & 400 & 0.86 & $\mathrm{DCP}$ & 90 & 2668 & {$[18]$} \\
\hline 10 & 400 & 0.86 & $\mathrm{DCP}$ & 90 & 2730 & {$[18]$} \\
\hline 10 & 400 & 0.86 & DCP & 90 & 2668 & {$[18]$} \\
\hline 10.1 & 100 & 40 & Benzoin & 1 & 2500 & {$[16]$} \\
\hline
\end{tabular}




\begin{tabular}{|c|c|c|c|c|c|c|}
\hline 10.9 & 100 & 40 & Benzoin & 1 & 2250 & [16] \\
\hline 14.1 & 50 & 2 & Benzoin & 1 & 2367 & [20] \\
\hline 14.6 & 50 & 2 & Benzoin & 1 & 2473 & [20] \\
\hline 14.6 & 50 & 2 & MMMP & 1 & 2483 & [20] \\
\hline 15.0 & 100 & 2 & Benzoin & 1.1 & 2496 & [20] \\
\hline 15.7 & 100 & 2 & MMMP & 1.0 & 2697 & [20] \\
\hline 15.8 & 100 & 2 & Benzoin & 1.1 & 2695 & [20] \\
\hline 15.8 & 100 & 2 & MMMP & 1.0 & 2619 & [20] \\
\hline 16.2 & 50 & 2 & MMMP & 1.0 & 2551 & [20] \\
\hline 19.8 & 500 & 1.5 & DMPA & 5 & 3680 & [17] \\
\hline 20 & $25-100$ & & Benzoin & & 2830 & [15] \\
\hline 20 & $25-100$ & & Benzoin & & 3005 & [15] \\
\hline 25 & $25-100$ & & Benzoin & & 3412 & [15] \\
\hline 25 & $25-100$ & & Benzoin & & 3605 & [15] \\
\hline 25 & $25-100$ & & Benzoin & & 3630 & [15] \\
\hline 25 & 400 & 0.86 & DCP & 90 & 3940 & [18] \\
\hline 25 & 400 & 0.86 & DCP & 90 & 3851 & [18] \\
\hline 25 & 400 & 0.86 & DCP & 90 & 3940 & [18] \\
\hline 25 & 400 & 0.86 & DCP & 90 & 3940 & [18] \\
\hline 25.2 & 100 & 4 & Benzoin & 5 & 3166 & [19] \\
\hline 25.2 & 200 & 4 & Benzoin & 5 & 3439 & [19] \\
\hline 25.2 & 300 & 4 & Benzoin & 5 & 3597 & [19] \\
\hline 25.2 & 400 & 4 & Benzoin & 5 & 3711 & [19] \\
\hline 25.2 & 500 & 4 & Benzoin & 5 & 3682 & [19] \\
\hline 26.7 & 50 & 2 & Benzoin & 1.1 & 3539 & [20] \\
\hline 26.9 & 50 & 2 & Benzoin & 1.1 & 3467 & [20] \\
\hline 26.9 & 50 & 2 & MMMP & 1.0 & 3800 & [20] \\
\hline
\end{tabular}




\begin{tabular}{|c|c|c|c|c|c|c|}
\hline 27.8 & 50 & 2 & MMMP & 1.0 & 3853 & [20] \\
\hline 28.0 & 100 & 2 & Benzoin & 1.2 & 3868 & [20] \\
\hline 28.2 & 100 & 2 & Benzoin & 1.2 & 3695 & [20] \\
\hline 28.2 & 100 & 2 & MMMP & 1.0 & 3910 & [20] \\
\hline 28.7 & 100 & 2 & MMMP & 1.0 & 3916 & [20] \\
\hline 28.9 & 50 & 30 & DMPA & 0.4 & 3720 & [16] \\
\hline 28.9 & 75 & 30 & DMPA & 0.4 & 4040 & [16] \\
\hline 28.9 & 75 & 30 & DMPA & 0.4 & 4040 & [16] \\
\hline 28.9 & 100 & 30 & DMPA & 0.4 & 4280 & [16] \\
\hline 28.9 & 100 & 30 & DMPA & 0.4 & 4210 & [16] \\
\hline 29.4 & 100 & 40 & DMPA & 1 & 4160 & [16] \\
\hline 29.4 & 100 & 40 & DMPA & 1 & 4160 & [16] \\
\hline 29.4 & 50 & 40 & DMPA & 1 & 3630 & [16] \\
\hline 29.4 & 50 & 40 & DMPA & 1 & 3160 & {$[16]$} \\
\hline 29.7 & 500 & 1.5 & DMPA & 5 & 5000 & [17] \\
\hline 30 & 100 & 5.7 & Benzoin & 5 & 3684 & [19] \\
\hline 30 & 100 & 5.7 & Benzoin & 5 & 3600 & [19] \\
\hline 30 & 100 & 5.7 & DMPA & 5 & 3437 & [19] \\
\hline 30 & 100 & 5.7 & DCP & 90 & 3490 & [19] \\
\hline 30 & 200 & 5.7 & Benzoin & 5 & 3996 & [19] \\
\hline 30 & 200 & 5.7 & DMPA & 5 & 3886 & [19] \\
\hline 30 & 300 & 5.7 & Benzoin & 5 & 3597 & [19] \\
\hline 30 & 400 & 5.7 & Benzoin & 5 & 3711 & [19] \\
\hline 30 & 400 & 5.7 & DMPA & 5 & 4021 & [19] \\
\hline 30 & 500 & 5.7 & Benzoin & 5 & 4108 & [19] \\
\hline 30 & 500 & 5.7 & DMPA & 5 & 4007 & [19] \\
\hline 30 & 500 & 5.7 & DCP & 90 & 4238 & [19] \\
\hline
\end{tabular}




\begin{tabular}{|c|c|c|c|c|c|c|}
\hline 30.1 & 500 & 1.5 & DMPA & 5 & 5130 & [17] \\
\hline 39.8 & 500 & 1.5 & DMPA & 5 & 6320 & [17] \\
\hline 40 & $25-100$ & & Benzoin & & 5432 & [15] \\
\hline 40 & $25-100$ & & Benzoin & & 5514 & [15] \\
\hline 40 & 100 & 3.5 & Benzoin & 5 & 4660 & [19] \\
\hline 40 & 200 & 3.5 & Benzoin & 5 & 4669 & [19] \\
\hline 40 & 300 & 3.5 & Benzoin & 5 & 5365 & [19] \\
\hline 40 & 400 & 3.5 & Benzoin & 5 & 5641 & [19] \\
\hline 40 & 500 & 3.5 & Benzoin & 5 & 5773 & [19] \\
\hline 40.2 & 500 & 1.5 & DMPA & 5 & 5980 & {$[17]$} \\
\hline 40.5 & 100 & 1.5 & DMPA & 5 & 4850 & [17] \\
\hline 40.5 & 150 & 1.5 & DMPA & 5 & 5820 & [17] \\
\hline 40.5 & 250 & 1.5 & DMPA & 5 & 6250 & [17] \\
\hline 40.5 & 500 & 1.5 & DMPA & 5 & 6450 & [17] \\
\hline 40.5 & 100 & 2.63 & DCP & 90 & 4768 & [18] \\
\hline 40.5 & 100 & 2.63 & DCP & 90 & 4823 & [18] \\
\hline 40.5 & 200 & 2.63 & DCP & 90 & 5255 & [18] \\
\hline 40.5 & 200 & 2.63 & $\mathrm{DCP}$ & 90 & 5285 & [18] \\
\hline 40.5 & 200 & 2.63 & $\mathrm{DCP}$ & 90 & 5142 & [18] \\
\hline 40.5 & 200 & 2.63 & DCP & 90 & 4992 & [18] \\
\hline 40.5 & 300 & 2.63 & $\mathrm{DCP}$ & 90 & 5603 & [18] \\
\hline 40.5 & 300 & 2.63 & $\mathrm{DCP}$ & 90 & 5603 & [18] \\
\hline 40.5 & 300 & 2.63 & $\mathrm{DCP}$ & 90 & 5638 & [18] \\
\hline 40.5 & 300 & 2.63 & DCP & 90 & 5603 & [18] \\
\hline 40.5 & 400 & 2.63 & DCP & 90 & 5868 & [18] \\
\hline 40.5 & 400 & 2.63 & DCP & 90 & 5829 & [18] \\
\hline 40.5 & 400 & 2.63 & DCP & 90 & 5599 & [18] \\
\hline
\end{tabular}




\begin{tabular}{|c|c|c|c|c|c|c|}
\hline 40.5 & 400 & 2.63 & DCP & 90 & 5475 & [18] \\
\hline 40.5 & 50 & 0.86 & DCP & 90 & 5399 & [18] \\
\hline 40.5 & 50 & 0.86 & DCP & 90 & 5525 & [18] \\
\hline 40.5 & 50 & 0.86 & DCP & 90 & 5461 & [18] \\
\hline 40.5 & 50 & 0.86 & DCP & 90 & 6199 & [18] \\
\hline 40.5 & 100 & 0.86 & DCP & 90 & 5412 & [18] \\
\hline 40.5 & 100 & 0.86 & DCP & 90 & 5412 & [18] \\
\hline 40.5 & 100 & 0.86 & DCP & 90 & 5538 & [18] \\
\hline 40.5 & 100 & 0.86 & DCP & 90 & 5667 & [18] \\
\hline 40.5 & 400 & 0.86 & DCP & 90 & 6388 & [18] \\
\hline 40.5 & 400 & 0.86 & $\mathrm{DCP}$ & 90 & 6243 & [18] \\
\hline 40.5 & 400 & 0.86 & DCP & 90 & 5694 & [18] \\
\hline 40.5 & 400 & 0.86 & DCP & 90 & 5826 & [18] \\
\hline 42.2 & 50 & 2 & Benzoin & 1.0 & 5074 & [20] \\
\hline 42.3 & 50 & 2 & Benzoin & 1.0 & 5015 & [20] \\
\hline 43.3 & 50 & 2 & MMMP & 0.9 & 5196 & [20] \\
\hline 44.2 & 100 & 2 & Benzoin & 1.0 & 5596 & [20] \\
\hline 44.8 & 100 & 2 & Benzoin & 1.0 & 5550 & [20] \\
\hline 44.9 & 50 & 2 & MMMP & 0.9 & 5510 & [20] \\
\hline 45.0 & 100 & 2 & MMMP & 0.9 & 5691 & [20] \\
\hline 45.3 & 100 & 2 & MMMP & 0.9 & 5845 & [20] \\
\hline 49.9 & 500 & 1.5 & DMPA & 5 & 7950 & [17] \\
\hline 50 & $25-100$ & & Benzoin & & 6634 & [15] \\
\hline 50 & $25-100$ & & Benzoin & & 6688 & [15] \\
\hline 50 & $25-100$ & & Benzoin & & 6974 & [15] \\
\hline 50 & 400 & 0.86 & DCP & 90 & 7613 & [18] \\
\hline 50 & 400 & 0.86 & DCP & 90 & 7613 & [18] \\
\hline
\end{tabular}




\begin{tabular}{|c|c|c|c|c|c|c|}
\hline 50 & 400 & 0.86 & $\mathrm{DCP}$ & 90 & 7790 & [18] \\
\hline 50 & 400 & 0.86 & DCP & 90 & 7790 & [18] \\
\hline 50 & 100 & 3.7 & Benzoin & 5 & 5855 & [19] \\
\hline 50 & 100 & 3.7 & Benzoin & 5 & 5860 & [19] \\
\hline 50 & 100 & 3.7 & Benzoin & 5 & 5738 & [19] \\
\hline 50 & 100 & 3.7 & Benzoin & 5 & 6081 & [19] \\
\hline 50 & 200 & 3.7 & Benzoin & 5 & 6328 & [19] \\
\hline 50 & 200 & 3.7 & DMPA & 5 & 5845 & [19] \\
\hline 50 & 200 & 3.7 & DMPA & 5 & 6171 & [19] \\
\hline 50 & 200 & 3.7 & DCP & 90 & 7291 & [19] \\
\hline 50 & 200 & 3.7 & DCP & 90 & 6159 & [19] \\
\hline 50 & 300 & 3.7 & Benzoin & 5 & 6982 & [19] \\
\hline 50 & 300 & 3.7 & DMPA & 5 & 6673 & [19] \\
\hline 50 & 300 & 3.7 & DCP & 90 & 6866 & [19] \\
\hline 50 & 400 & 3.7 & Benzoin & 5 & 6750 & [19] \\
\hline 50 & 400 & 3.7 & DMPA & 5 & 6992 & [19] \\
\hline 50 & 400 & 3.7 & DCP & 90 & 7562 & [19] \\
\hline 50 & 500 & 3.7 & Benzoin & 5 & 7412 & [19] \\
\hline 50 & 500 & 3.7 & Benzoin & 5 & 7427 & [19] \\
\hline 50 & 500 & 3.7 & Benzoin & 5 & 7850 & [19] \\
\hline 50 & 500 & 3.7 & Benzoin & 5 & 7683 & [19] \\
\hline 50 & 500 & 3.7 & DMPA & 5 & 7097 & [19] \\
\hline 50 & 500 & 3.7 & $\mathrm{DCP}$ & 90 & 7573 & [19] \\
\hline 50.5 & 500 & 1.5 & DMPA & 5 & 7990 & [17] \\
\hline 54.4 & 50 & 40 & DMPA & 1 & 6110 & [16] \\
\hline 55 & $25-100$ & & Benzoin & & 7187 & [15] \\
\hline 55 & $25-100$ & & Benzoin & & 7259 & [15] \\
\hline
\end{tabular}




\begin{tabular}{|c|c|c|c|c|c|c|}
\hline 55.5 & 100 & 40 & DMPA & 1 & 7430 & [16] \\
\hline 57.3 & 50 & 2 & Benzoin & 0.9 & 6618 & [20] \\
\hline 57.3 & 50 & 2 & Benzoin & 0.9 & 6411 & [20] \\
\hline 58.8 & 50 & 2 & MMMP & 0.9 & 6262 & [20] \\
\hline 58.9 & 50 & 2 & MMMP & 0.9 & 6157 & [20] \\
\hline 59.1 & 100 & 2 & Benzoin & 1.0 & 7962 & [20] \\
\hline 59.6 & 100 & 2 & Benzoin & 1.0 & 8013 & [20] \\
\hline 60 & $25-100$ & & Benzoin & & 8778 & [15] \\
\hline 60 & $25-100$ & & Benzoin & & 9136 & [15] \\
\hline 60 & 400 & 0.86 & DCP & 90 & 9509 & [18] \\
\hline 60 & 400 & 0.86 & DCP & 90 & 9662 & [18] \\
\hline 60 & 100 & 3.5 & Benzoin & 5 & 7305 & [19] \\
\hline 60 & 200 & 3.5 & Benzoin & 5 & 8257 & [19] \\
\hline 60 & 300 & 3.5 & Benzoin & 5 & 8730 & [19] \\
\hline 60 & 400 & 3.5 & Benzoin & 5 & 9300 & [19] \\
\hline 60 & 500 & 3.5 & Benzoin & 5 & 9823 & [19] \\
\hline 60.2 & 500 & 1.5 & DMPA & 5 & 10580 & [17] \\
\hline 60.4 & 500 & 1.5 & DMPA & 5 & 10430 & [17] \\
\hline 60.8 & 100 & 2 & MMMP & 0.9 & 7916 & [20] \\
\hline 61.2 & 100 & 2 & MMMP & 0.9 & 7878 & [20] \\
\hline 65 & 100 & 4.3 & Benzoin & 5 & 8376 & [19] \\
\hline 65 & 200 & 4.3 & Benzoin & 5 & 8269 & [19] \\
\hline 65 & 300 & 4.3 & Benzoin & 5 & 9380 & [19] \\
\hline 65 & 400 & 4.3 & Benzoin & 5 & 9425 & [19] \\
\hline 65 & 500 & 4.3 & Benzoin & 5 & 10587 & [19] \\
\hline 69.5 & 500 & 1.5 & DMPA & 5 & 12880 & [17] \\
\hline 70.2 & 500 & 1.5 & DMPA & 5 & 13700 & [17] \\
\hline
\end{tabular}


${ }^{a}$ Specific information on prr and photoinitiator concentration for individual experiments reported in reference [15] is not available.

The $k_{\mathrm{p}}$ estimates from the individual PLP-SEC experiments at 10,30 , and $50{ }^{\circ} \mathrm{C}$ are plotted as a function of prr in Figure 1. The scatter seen at each temperature/prr condition is typical when compared with other $k_{\mathrm{p}}$ benchmark data sets. ${ }^{[3],[5]-[10]}$ To determine whether the variation with prr is systematic, the global fit of the Arrhenius equation to the complete data set is compared with the fits of the data measured at lower prr $(\leq 100 \mathrm{~Hz})$ and higher prr $(\geq 300 \mathrm{~Hz})$.

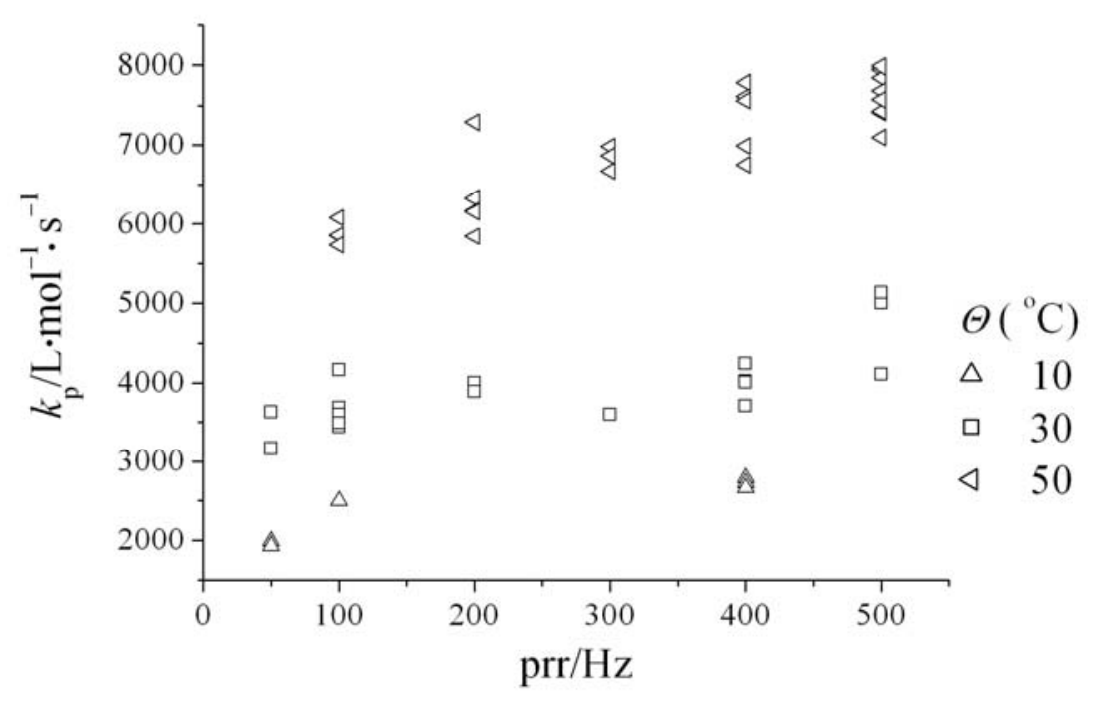

Figure 1. Propagation rate coefficient, $k_{\mathrm{p}}$, vs. pulse repetition rate, prr, for bulk vinyl acetate as determined by PLP-SEC experiments at 10,30 , and $50^{\circ} \mathrm{C}$, as indicated.

The results of the linear least-squares fitting of the Arrhenius relation $\ln \left(k_{\mathrm{p}}\right)=$ $\ln (A)-E_{\mathrm{A}} / R T$ are summarized in Table 2 and plotted in Figures 2 and 3 . The fit to the overall data set of 178 experiments from Table 1 for the temperature range of 4.7 to $70.2{ }^{\circ} \mathrm{C}$ is given by Equation (2).

$$
\ln \left[k_{\mathrm{p}} /\left(\mathrm{L} \cdot \mathrm{mol}^{-1} \cdot \mathrm{s}^{-1}\right)\right]=16.42-2455 \cdot T^{-1} / K^{-1}
$$

The associated pre-exponential factor $A$ and activation energy $E_{\mathrm{A}}$ are $1.35 \times 10^{7} \mathrm{~L} \cdot \mathrm{mol}^{-1} \cdot \mathrm{s}^{-1}$ and $20.4 \mathrm{~kJ} \cdot \mathrm{mol}^{-1}$, respectively. 
The principal source of the data scatter in Figure 2 is the influence of prr on $k_{\mathrm{p}}$, as can be seen from the Figure 3 comparison of the overall fit with the fits to the low prr and high prr data sets. As summarized in Table 2, the $k_{\mathrm{p}}$ value calculated at $50{ }^{\circ} \mathrm{C}$ using the "low prr" fit is $15 \%$ lower than the value calculated from the "high prr" fit. Both estimates, however, are within 10\% of the $k_{\mathrm{p}}$ value calculated using the entire data set. Moreover, the $95 \%$ joint confidence intervals for the $A$ and $E_{\mathrm{A}}$ estimates overlap, as shown in Figure 4; these ellipsoids were determined by non-linear least-squares ${ }^{[22]}$ fitting with weighting on the basis of a constant relative error in individual $k_{\mathrm{p}}$ measurements. For VAc, the activation energy is in the range of 19.2 to 21.1 $\mathrm{kJ} \cdot \mathrm{mol}^{-1}$ and the preexponential factor is $0.83 \times 10^{7}$ to $1.76 \times 10^{7} \mathrm{~L} \cdot \mathrm{mol}^{-1} \cdot \mathrm{s}^{-1}$. In this context, note that the Arrhenius parameters deduced from both linear and nonlinear fitting are identical within experimental accuracy. The confidence interval for the complete VAc data set is of similar size to that determined from the benchmark set of methyl acrylate. ${ }^{[10]}$

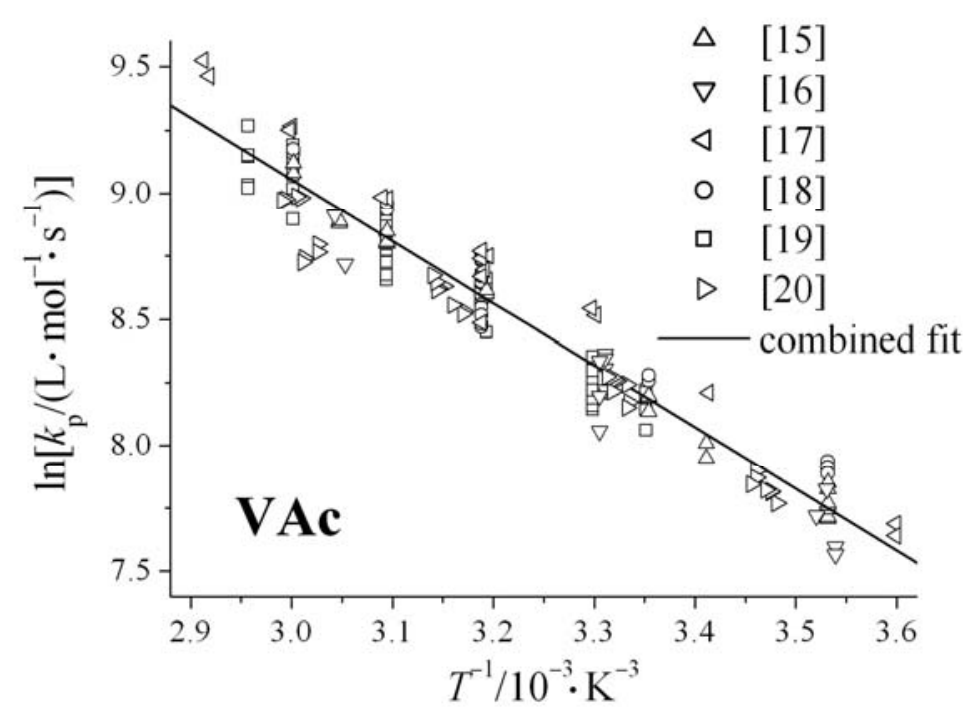

Figure 2. Arrhenius plot of all Table 1 values of the propagation rate coefficient, $k_{\mathrm{p}}$, for bulk vinyl acetate polymerization. Equation (2), the best-fit line to all the points, is also shown. 


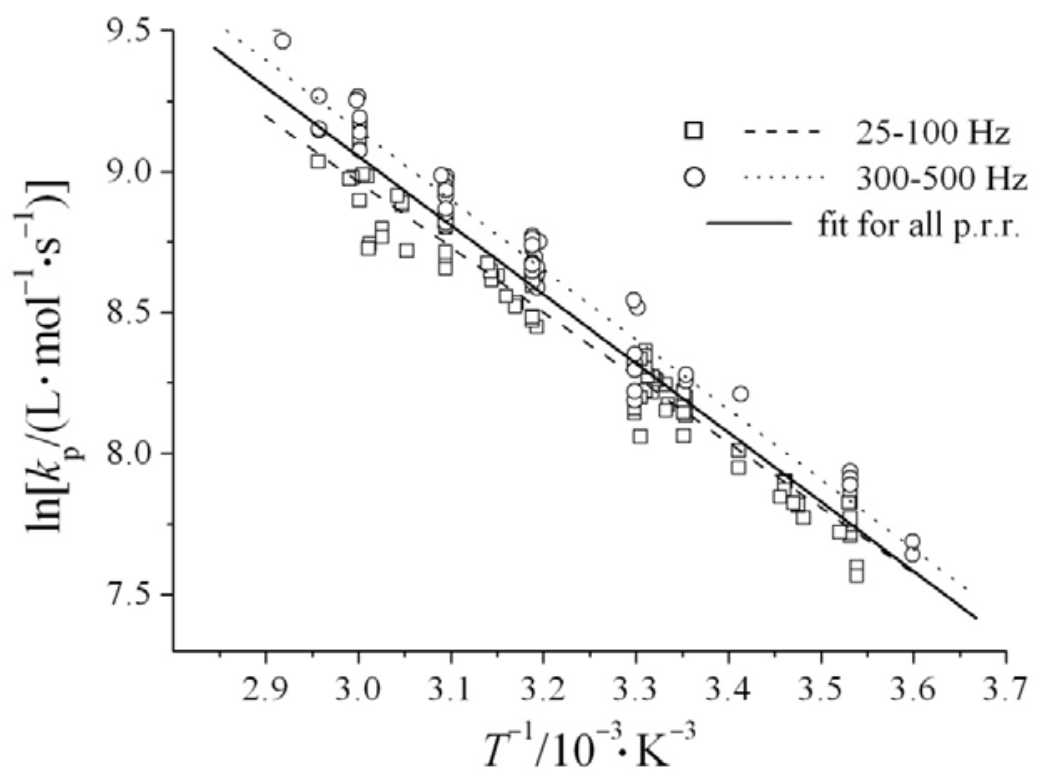

Figure 3. A comparison of the Arrhenius fits to $k_{\mathrm{p}}$ values for bulk vinyl acetate obtained from PLP-SEC experiments conducted at lower prr $(25-100 \mathrm{~Hz})$ and higher prr $(300-500 \mathrm{~Hz})$ with the fit of the entire Table 1 data set, viz. Equation (2). The associated Arrhenius parameters are given in Table 2.

Table 2. Arrhenius parameters for bulk vinyl acetate obtained by fitting of Table 1 data measured by PLP-SEC in the specified intervals of pulse repetition rates (prr).

\begin{tabular}{|c|c|c|c|c|}
\hline $\begin{array}{c}\text { prr range } \\
\mathrm{Hz}\end{array}$ & $\begin{array}{c}N \\
\text { number of } \\
\text { points }\end{array}$ & $\begin{array}{c}A / \\
\mathrm{L} \cdot \mathrm{mol}^{-1} \cdot \mathrm{s}^{-1}\end{array}$ & $\begin{array}{c}E_{\mathrm{A}} / \\
\mathrm{kJ} \cdot \mathrm{mol}^{-1}\end{array}$ & $\begin{array}{c}k_{\mathrm{p}} \text { at } 50{ }^{\circ} \mathrm{C} / \\
\mathrm{L} \cdot \mathrm{mol}^{-1} \cdot \mathrm{s}^{-1}\end{array}$ \\
\hline $25-500$ & 178 & $1.35 \times 10^{7}$ & 20.4 & 6800 \\
\hline $25-100$ & 95 & $8.09 \times 10^{6}$ & 19.2 & 6370 \\
\hline $300-500$ & 67 & $1.59 \times 10^{7}$ & 20.6 & 7440 \\
\hline
\end{tabular}




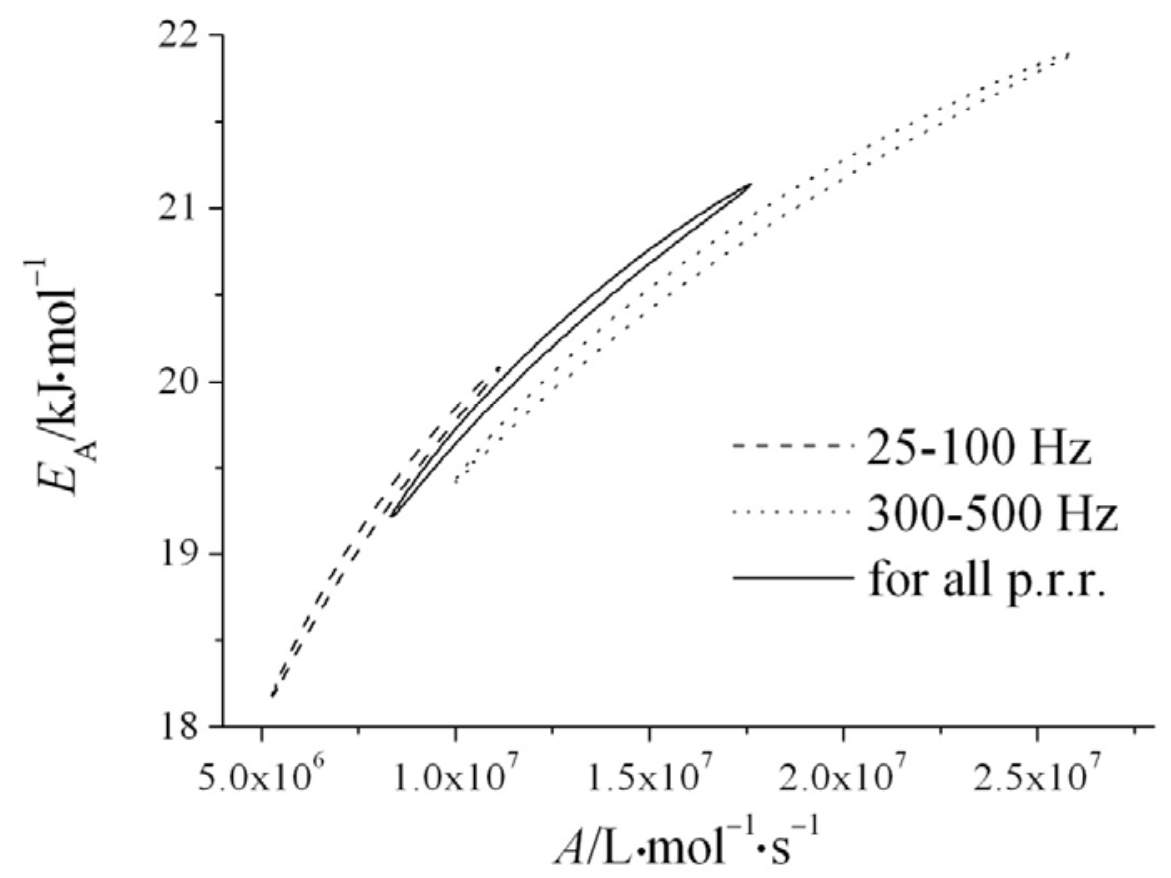

Figure 4. 95\% joint-confidence intervals for the Arrhenius parameters for $k_{\mathrm{p}}$ of bulk vinyl acetate polymerization, as estimated from fitting of the data in Table 1 (see text and Figure 3).

The Arrhenius parameters estimated by electron paramagnetic resonance (EPR) spectroscopy for vinyl pivalate in heptane solution $\left(E_{\mathrm{A}}=20.5 \mathrm{~kJ} \cdot \mathrm{mol}^{-1}, A=1.39 \times 10^{7}\right.$ $\left.\mathrm{L} \cdot \mathrm{mol}^{-1} \cdot \mathrm{s}^{-1}\right)^{[23]}$ are surprisingly close to the VAc values of Equation (2), although a recent study using the PLP-SEC method results in significantly different values for bulk vinyl pivalate $\left(E_{\mathrm{A}}=\right.$ $\left.17.4 \mathrm{~kJ} \cdot \mathrm{mol}^{-1}, A=6.78 \times 10^{6} \mathrm{~L} \cdot \mathrm{mol}^{-1} \cdot \mathrm{s}^{-1}\right) .{ }^{[21]}$ This makes clear that additional investigations are necessary to further explore the propagation behavior of the vinyl ester family.

\section{Discussion}

From the analysis of the combined data set, a small but systematic increase in the PLPdetermined $k_{\mathrm{p}}$ values with increasing laser prr was found, as also observed in individual studies of VAc propagation kinetics. ${ }^{[17],[19]}$ While a definitive cause for this behavior has not been identified, various hypotheses are considered below. 
a) Chain-length dependent propagation (CLDP). Very small radicals propagate faster than long radicals. ${ }^{[24]}$ It is known that a dependence of the propagation rate coefficient on radical chain length can lead to some variation in the $k_{\mathrm{p}}$ values estimated by the PLP technique. ${ }^{[25]}$ Specifically, if prr is increased, then growth time between pulses is reduced such that radicals achieve a shorter chain length between pulses and thus have a slightly higher apparent $k_{\mathrm{p}}$ value due to CLDP. While this explanation is qualitatively consistent with VAc results, the chain lengths reached under PLP conditions are greater than 100 for the vast majority of the Table 1 data (except for $10{ }^{\circ} \mathrm{C}$ pulsed at $500 \mathrm{~Hz}$ ) and there is no reason to expect VAc to exhibit a stronger CLDP than methyl methacrylate (MMA) or styrene, both of which show a somewhat smaller $k_{\mathrm{p}}$ dependence on prr than is observed here. ${ }^{[24]}$ In fact it took many years before this small effect (under standard conditions) was recognized as a genuine effect in MMA and styrene data rather than just being noise. ${ }^{[26]}$ Furthermore, reported chain-length-dependent $k_{\mathrm{p}}$ values at high chain lengths have been attributed to SEC column band broadening effects. ${ }^{[27]}$ (Note that more discussion of the influence of SEC broadening on PLP analysis is found in previous IUPAC benchmark publications. ${ }^{[5],[10]}$ ) In addition, chain-length dependence of propagation is not associated with a loss of structure in the polymer MMDs, as is observed with VAc at low prr. ${ }^{[14],[19]}$

A related factor to consider is the first addition step in the chain-growth process, in which the primary radical generated by photoinitiator decomposition adds to VAc monomer. It is known that addition of radicals to VAc monomer is reduced relative to addition to other monomers, as seen by copolymerization study of VAc with acrylates, methacrylates, and styrene. ${ }^{[28],[29]}$ It is also known that the rate of VAc (co)polymerization is retarded in aromatic solvents such as toluene, due to slow addition of monomer to the toluene radical formed after transfer to solvent. ${ }^{[30]-[32]}$ For effective PLP experimentation, both radicals formed by decomposition of the photoinitiator must be sufficiently active to attack the VAc double bond; if 
not, the efficiency of initiation suffers as half of the primary radicals formed are only able to terminate existing growing chains rather than initiate new ones. ${ }^{[33]}$ A related factor is the concentration of radicals generated by the laser pulse which, along with prr, influences the overall shape of the distribution and thus the determination of $k_{\mathrm{p}}$ (see point $c$ below). Nonetheless, the dependence of $k_{\mathrm{p}}$ on pulse repetition rate has been found to be independent of choice of the photoinitiator, ${ }^{[19],[20]}$ suggesting that the lowered propensity of VAc monomer to radical attack is not the reason for the observed behavior.

Before proceeding it is noted that if CLDP is the cause of the prr dependence in Figures 1 and 3 , then the 'true' value of $k_{\mathrm{p}}$, that for long chains, is the value at low prr.

b) Intramolecular chain transfer to polymer. In the PLP experiments carried out at $40.5^{\circ} \mathrm{C}$ by Junkers et al., ${ }^{[17]}$ the $k_{\mathrm{p}}$ value increased by $30 \%$ as prr was increased from 100 to 500 Hz. This effect is qualitatively the same as with acrylates (see above). As VAc is a constitutional isomer of methyl acrylate, Junkers et al. ${ }^{[17]}$ suggested that backbiting occurs in VAc systems, and is the main reason for the observed increase in $k_{\mathrm{p}}$ with prr. However, this hypothesis is contradicted by branching studies that show intramolecular transfer to polymer during VAc homopolymerization and copolymerization with ethylene is negligible or very low relative to corresponding acrylate systems. ${ }^{[34]-[36]}$ Furthermore, Kattner and Buback ${ }^{[33]}$ did not detect midchain VAc radicals via EPR probing of the radical population, despite using conditions under which MCRs are prevalent for acrylates. Thus, it can be concluded that intramolecular chain transfer to polymer is not likely to be the reason for the prr dependence of VAc $k_{\mathrm{p}}$.

Furthermore, what drives backbiting in acrylates is that the backbone $\mathrm{C}-\mathrm{H}$ bonds are activated by adjacent carbonyl bonds. ${ }^{[37]}$ However, with VAc there is no chemical driving force for radical attack of the polymer backbone due to the presence of the oxygen atom adjacent to the backbone $\mathrm{C}-\mathrm{H}$. On the other hand, the pendant methyl group of VAc is rendered labile by the adjacent carbonyl group. This may lead to enhanced chain transfer to monomer (e.g., relative to 
methyl acrylate) under PLP conditions, a reaction that can result in broadened, featureless MMDs at lower prr. Indeed, chain transfer to monomer was proposed as a possible explanation for the difficulties in obtaining good PLP structure at low prr $(<25 \mathrm{~Hz}) \cdot{ }^{[14],[15]}$ However, wellstructured MMDs are produced at the higher repetition rates used to generate the benchmark data compiled within this paper, and simulations have shown that transfer is not likely to interfere with $k_{\mathrm{p}}$ determination under these conditions. ${ }^{[19]}$

Before proceeding it is noted that if intramolecular chain transfer is the cause of prr variation of VAc $k_{\mathrm{p}}$, then the values measured at high prr more closely corresponds to CER propagation.

c) Polymerization at the high-termination limit. To explain their difficulties in the estimation of $k_{\mathrm{p}}$ from MMDs generated by $10 \mathrm{~Hz}$ PLP experiments for VAc, Hutchinson et al. hypothesized that the distributions were measured at the so-called high-termination-rate limit (HTRL). ${ }^{[14]}$ In this regime of PLP operation, the radical concentration remaining in the system is so low when the next pulse arrives that the new pulse eliminates practically all those radicals that remain. Thus, the population of radicals reaching a chain length $2 k_{\mathrm{p}}[\mathrm{M}] t_{\mathrm{d}}$ is not sufficient to produce an observable second peak in the first-derivative of the MMD, and the principal consistency criterion for the PLP-SEC method is not satisfied. By decreasing the concentration of initiator, Hutchinson et al. postulated that they were shifting the system away from the HTRL, and that this was the reason for successfully applying the PLP-SEC method up to $25{ }^{\circ} \mathrm{C}$ at 10 Hz. ${ }^{[14]}$

This explanation has been revisited by Kattner, ${ }^{[18]}$ who considers that the VAc system moves towards the HTRL as pulse repetition rate is decreased from 500 to $100 \mathrm{~Hz}$. At conditions at or close to this limit, the value of $k_{\mathrm{p}}$ estimated from the inflection point of the MMD will be slightly lower than the true value, ${ }^{[34],[39]}$ consistent with the observed effect of prr on VAc $k_{\mathrm{p}}$ seen in Figure 1. Furthermore, such a trend will be accentuated by SEC column broadening. ${ }^{[5],[27]}$ 
Kattner showed that a decrease of pulse energy (an effect similar to a decrease in photoinitiator concentration) shifts the system away from the HTRL and allows the determination of $k_{\mathrm{p}}$ at lower pulse repetition rates. ${ }^{[18]}$ However, experiments by Monyatsi et al. ${ }^{[19]}$ found that $k_{\mathrm{p}}$ varies with prr in the same way for three different photoinitiators, despite differences in the resulting MMD shapes being an indication of differences in the radical concentration generated per pulse. The accompanying simulation study ${ }^{[19]}$ concluded that the influence of termination rate on the shape of the MMD results in less than a $10 \%$ decrease in $k_{\mathrm{p}}$ as prr is decreased from 500 to 100 $\mathrm{Hz}$, a variation that is lower than that observed experimentally.

In summary, if termination-rate limit is the reason for the prr variation of VAc $k_{\mathrm{p}}$, then the values in Table 1 are systematically low at low prr (because under such conditions the point of inflection underestimates the true $k_{\mathrm{p}}$ ) while measurements at high prr will be closer to the true $k_{\mathrm{p}}$ value.

d) Head-to-head addition. A complicating factor in the propagation kinetics in VAc polymerization is the occurrence of 1 to $2 \%$ head-to-head addition, as first reported by Flory and Leutner. $^{[40]}$ The head-to-head addition is a result of the low reactivity of VAc towards attack, such that radicals occasionally add across the monomer $\mathrm{COC}(\mathrm{O}) \mathrm{CH}_{3}$ "head" rather than the less sterically-hindered $\mathrm{CH}_{2}$ "tail" of the monomer. Considering head-to-head additions, the possible modes of radical propagation associated with monomer structure are shown in Scheme 1. For most monomers, the microstructure of the polymer chains produced indicates that head-to-tail propagation occurs exclusively, as this addition is favored on both steric and resonance grounds. For this usual situation, the head-to-tail rate coefficient ( $k_{\mathrm{p}, \mathrm{ht}}$ in Scheme 1) can be considered as the sole homopropagation addition, and the other three addition mechanisms can be neglected. However, for monomers (such as VAc) for which the presence of head-to-head propagation is revealed, the kinetics of polymerization are more complicated, as four instead of one propagation reactions need to be considered. 

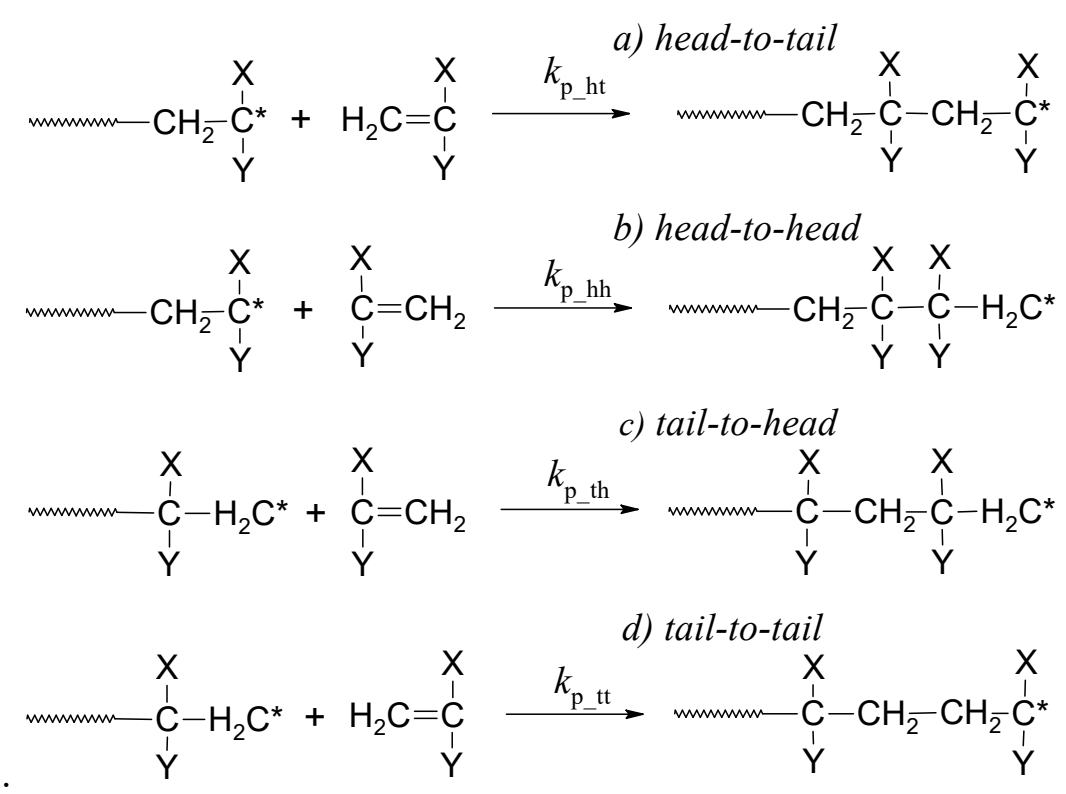

Scheme 1. The propagation reactions in radical homopolymerization, accounting for the possibility of inverted monomer addition. In the case of vinyl acetate $\mathrm{X}$ is $\mathrm{O}-\mathrm{CO}-\mathrm{CH}_{3}$ and $\mathrm{Y}$ is $\mathrm{H}$.

Equation (3) has been derived ${ }^{[19]}$ to describe the dependence of an averaged propagation rate coefficient, $k_{\mathrm{p}}^{\mathrm{av}}$, on the four addition steps in Scheme 1.

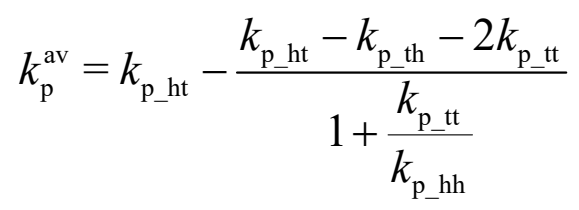

Note that the $k_{\mathrm{p}}^{\mathrm{av}}$ value does not change with varying monomer concentration in the system, and thus a single value can be used to describe VAc radical polymerization rate over the complete range of monomer conversion. However, the averaging is strictly valid only if the growing radicals are subjected to several cycles of transformation from normal radical to inverted (headto-head reaction in Scheme 1) and back from inverted radical to normal (tail-to-tail reaction in Scheme 1). At the higher pulse repetition rates used in pulsed-laser polymerization, it is hypothesized that the radicals do not have sufficient time to achieve this averaged growth rate, 
with the difference in values of $k_{\mathrm{p}_{-} \text {ht }}$ (higher) and $k_{\mathrm{p}}^{\mathrm{av}}$ (lower) causing the observed pulse repetition rate dependence. ${ }^{[19]}$ Under this scenario, the majority of radicals are not subjected to a head-to-head propagation defect when pulsed at high prr, meaning that analysis of the resulting MMD yields a $k_{\mathrm{p}}$ estimate close to $k_{\mathrm{p}_{-} \text {ht, }}$ while at low prr all radicals are subjected to multiple head-to-head propagation events, and thus yield a lower value that is closer to $k_{\mathrm{p}}^{\mathrm{av}}$; at intermediate prr, the PLP-determined $k_{\mathrm{p}}$ value is expected to increase from $k_{\mathrm{p}}^{\mathrm{av}}$ at low prr towards $k_{\mathrm{p}_{-} \mathrm{ht}}$ at prr of $500 \mathrm{~Hz}$.

Monyatsi et al. ${ }^{[19]}$ have shown that it is possible to select four microscopic propagation rate coefficients for VAc polymerization that explain the prr dependence of $k_{\mathrm{p}}$. As an addition coefficient that is favored on both steric and resonance grounds, $k_{\mathrm{p}_{-}}$t is higher than the others, with the relative value of $k_{\mathrm{p} \_}$hh set to satisfy the experimentally measured level of head-to-head addition ( 1 to $2 \%$ ). It was found that the apparent dependence of $k_{\mathrm{p}}$ on pulse repetition rate could only be matched if the rates of addition of monomer to the "tail" radical ( $k_{\mathrm{p}_{-}}$th and $\left.k_{\mathrm{p}_{-} \mathrm{tt}}\right)$ was reduced by a factor of 50 to 100 compared with the rate of head-to-tail addition. While no independent measurements of the individual microscopic rate coefficients are available, the simulations provide an idea of the order of magnitude decrease in "tail" radical activity required to explain the experimentally observed variation in $k_{\mathrm{p}}$ with prr. However, with these parameter values a significant fraction of the radicals $(\sim 30 \%)$ were predicted to be in the inverted "tail" state, in conflict with the study of VAc by Kattner and Buback using EPR spectroscopy, in which only the "head" radical structure was observed. ${ }^{[33]}$ It is important to note that the simulation study by Monyatsi et al. ${ }^{[19]}$ also indicated that all experimental data may be fit with a single Arrhenius fit to yield a reasonable estimate of $k_{\mathrm{p}}^{\mathrm{av}}$.

Summing up this subsection, if there are head-to-head effects on overall $k_{\mathrm{p}}$, then it is the measured values at high prr that corresponds more closely to a microscopic $k_{\mathrm{p}}$, namely that of head-to-tail addition. 
Summary and perspectives. The four explanations that have been presented are all consistent with the observed dependence of $k_{\mathrm{p}}$ on prr. It is quite likely that two or more of these effects are contributing to the observed trend. In the case of CLDP it will be the low-prr value that corresponds to a microscopic $k_{\text {p }}$, namely that for long chains, while at intermediate and high prr the $k_{\mathrm{p}}$ that is observed will be an averaged one, in this case over chain lengths. On the other hand, for the other three effects it is the high-prr value of $k_{\mathrm{p}}$ that has microscopic meaning; in case (c) the lower-prr values are simply underestimates, while in the other two cases they are averages over radical type (CERs and MCRs in the case of (b), head and tail in the case of (d). This discussion suggests that it is possible that there is some sort of cancellation of effects, and thus the $k_{\mathrm{p}}$ at intermediate prr - as encapsulated in Equation (2) - is recommended for general use.

Lastly, it is interesting to consider the generality of effects (a)-(d). Of the monomers thus far studied by PLP-SEC, backbiting is only expected to operate for acrylate-like systems, while head-to-head addition is specific to vinyl esters. However, CLDP should be operative for all monomers, as should be the HTRL (although the specific conditions in which it is realized will vary from monomer to monomer). So it is well to be aware that there should always be some minor variation of $k_{\mathrm{p}}$ with prr using the PLP-SEC technique, as evidenced in this work. For VAc this effect is larger than for methacrylate and styrenic monomers, perhaps due to the larger range of prr encompassed by the benchmark data set.

\section{Conclusion}

From the simulation and experimental studies summarized above, it is evident that systematic variations in the $k_{\mathrm{p}}$ values determined for bulk VAc from MMDs generated over such a broad range of pulse repetition rates $(25-500 \mathrm{~Hz})$ can arise from multiple factors, including SEC band broadening, the changing shape of the MMD as it moves from high-termination toward low- 
termination conditions with increasing pulse repetition rate, and the influence of head-to-head addition. Since all of the data included in Table 1 meet the established PLP consistency criteria, we conclude that, despite the small systematic variation in $k_{\mathrm{p}}$ estimates with prr, no values should be excluded from the benchmark data set. Thus, we recommend that the best-fit Arrhenius parameters of Equation 2 be used to represent the propagation kinetics of bulk VAc.

The benchmark data derived from application of the PLP-SEC technique were collected from six research groups covering the temperature range of 4.7 to $70.2{ }^{\circ} \mathrm{C}$. The benchmark activation energy for vinyl acetate $\left(E_{\mathrm{A}}=20.4 \mathrm{~kJ} \cdot \mathrm{mol}^{-1}\right)$ is intermediate between the benchmark values for methyl acrylate $\left(E_{\mathrm{A}}=17.3 \mathrm{~kJ} \cdot \mathrm{mol}^{-1}\right)^{[10]}$ and methyl methacrylate $\left(E_{\mathrm{A}}=22.36\right.$ $\left.\mathrm{kJ} \cdot \mathrm{mol}^{-1}\right),{ }^{[5]}$ with the pre-exponential factor $\left(A=1.35 \times 10^{7} \mathrm{~L} \cdot \mathrm{mol}^{-1} \cdot \mathrm{s}^{-1}\right)$ similar to that for methyl acrylate $\left(1.41 \times 10^{7} \mathrm{~L} \cdot \mathrm{mol}^{-1} \cdot \mathrm{s}^{-1}\right)^{[10]}$ and almost an order of magnitude higher than that of methyl methacrylate $\left(2.67 \times 10^{6} \mathrm{~L} \cdot \mathrm{mol}^{-1} \cdot \mathrm{s}^{-1}\right) \cdot{ }^{[5]}$ With these Arrhenius parameters $k_{\mathrm{p}}$ values of 323,3660 and $13100 \mathrm{~L} \cdot \mathrm{mol}^{-1} \cdot \mathrm{s}^{-1}$ are calculated at $25^{\circ} \mathrm{C}$ for homopolymerization of methyl methacrylate, vinyl acetate and methyl acrylate, respectively. Thus, the propagation rate coefficient for vinyl acetate is more than 10 times greater than that for methyl methacrylate and almost 4 times less than that for methyl acrylate chain-end propagation.

\section{Acknowledgements}

The financial support of IUPAC via project 2013-045-1-400 is gratefully acknowledged.

\section{References}

1. O. F. Olaj, I. Bitai, F. Hinkelmann, Makromol. Chem., 1987, 188, 1689-1702.

2. M. Buback, M. Egorov, R. G. Gilbert, V. Kaminsky, O. F. Olaj, G. T. Russell, P. Vana, G. Zifferer, Macromol. Chem. Phys. 2002, 203, 2570-2582.

3. M. Buback, R. G. Gilbert, R. A. Hutchinson, B. Klumperman, F.-D. Kuchta, B. G. Manders, K. F. O’Driscoll, G. T. Russell, J. Schweer, Macromol. Chem. Phys. 1995, 196, 3267-3280. 
4. G. V. Schultz, J. Romatovski, Makromol. Chem. 1965, 85, 195-226.

5. S. Beuermann, M. Buback, T. P. Davis, R. G. Gilbert, R. A. Hutchinson, O. F. Olaj, G. T. Russell, J. Schweer, A. M. van Herk, Macromol. Chem. Phys. 1997, 198, 1545-1560.

6. S. Beuermann, M. Buback, T. P. Davis, R. G. Gilbert, R. A. Hutchinson, A. Kajiwara, B. Klumperman, G. T. Russell, Macromol. Chem. Phys. 2000, 201, 1355-1364.

7. S. Beuermann, M. Buback, T. P. Davis, N. García, R. G. Gilbert, R. A. Hutchinson, A. Kajiwara, M. Kamachi, I. Lacík, G. T. Russell, Macromol. Chem. Phys. 2003, 204, 1338-1350.

8. J. M. Asua, S. Beuermann, M. Buback, P. Castignolles, B. Charleux, R. G. Gilbert, R. A. Hutchinson, J. R. Leiza, A. N. Nikitin, J.-P. Vairon, A. M. van Herk, Macromol. Chem. Phys. 2004, 205, 2151-2160.

9. S. Beuermann, M. Buback, P. Hesse, F.-D. Kuchta, I. Lacík, A. M. van Herk, Pure Appl. Chem. 2007, 79, 1463-1469.

10. C. Barner-Kowollik, S. Beuermann, M. Buback, P. Castignolles, B. Charleux, M. L. Coote, R. A. Hutchinson, T. Junkers, I. Lacík, G. T. Russell, M. Stach, A. M. van Herk, Polym. Chem. 2013, 5, 204-212.

11. A. M. van Herk, Macromol. Rapid Commun. 2001, 22, 687-689.

12. C. Barner-Kowollik, F. Günzler and T. Junkers, Macromolecules 2008, 41, 8971-8973.

13. R. A. Hutchinson, M. T. Aronson, J. R. Richards, Macromolecules 1993, 26, 6410-6415.

14. R. A. Hutchinson, J. R. Richards, M. T. Aronson, Macromolecules 1994, 27, 4530-4537.

15. R. A. Hutchinson, D. A. Paquet, J. H. McMinn, S. Beuermann, R. E. Fuller, C. Jackson, DECHEMA Monographs 1995, 131, 467-492.

16. B. Manders, PhD thesis, TU Eindhoven, Eindhoven, Netherlands, 1997.

17. T. Junkers, D. Voll, C. Barner-Kowollik, E-Polymers 2009, no 076.

18. H. Kattner, M.Sc. Thesis, University of Göttingen, Göttingen, Germany, 2012.

19. O. Monyatsi, A. N. Nikitin, R. A. Hutchinson, Macromolecules 2014, 47, 8145-8153.

20. J. Rossberg, BSc Thesis, Universität Potsdam, Potsdam, Germany, 2010. 
21. O. Monyatsi, R. A. Hutchinson, Macromol. Chem. Phys. 2016, 217, 51-68.

22. A. M. van Herk, J. Chem. Educ. 1995, 72, 138-140.

23. N. Kubota, A. Kajiwara, P. B. Zetterlund, M. Kamachi, J. Treurnicht, M. P. Tonge, R. G. Gilbert, B. Yamada, Macromol. Chem. Phys. 2007, 208, 2403-2411.

24. J. P. A. Heuts, G. T. Russell, Eur. Polym. J. 2006, 42, 3-20.

25. A. N. Nikitin, A. V. Evseev, Macromol. Theory Simul. 1999, 8, 296-308.

26. O. F. Olaj, P. Vana, M. Zoder, A. Kornherr, G. Zifferer, Macromol. Rapid Commun. 2000, 21, 913-920.

27. R. X. E. Willemse, B. B. P. Staal, A. M. van Herk, S. C. J. Pierik, B. Klumperman, Macromolecules 2003, 36, 9797-9803.

28. F. R. Mayo, C. Walling, F. M. Lewis, W. F. Hulse, J. Am. Chem. Soc. 1948, 70, 1523-1525.

29. M. Dossi, K. Liang, R. A. Hutchinson, D. Moscatelli, J. Phys. Chem. B 2010, 114, 42134222.

30. M. J. Wisotsky, A. E. Kober, J. Appl. Polym. Sci. 1972, 16, 849-854.

31. T. F. McKenna, A. Villanueva, J. Polym. Sci. Part A: Polym. Chem. 1999, 37, 589-601.

32. D. E. Lonsdale, G. Johnston-Hall, A. Fawcett, C. A. Bell, C. N. Urbani, M. R. Whittaker, M. J. Monteiro, J. Polym. Sci. Part A: Polym. Chem. 2007, 45, 3620-3625.

33. H. Kattner, M. Buback, Macromol. Chem. Phys. 2014, 215, 1180-1191.

34. J. C. Randall, C. J. Ruff, M. Kelchtermans, B. H. Gregory, Macromolecules 1992, 25, 2624 2633.

35. E. F. McCord, W. H. Shaw Jr., R. A. Hutchinson, Macromolecules 1997, 30, 246-256.

36. D. Britton, F. Heatley, P. A. Lovell, Macromolecules 1998, 31, 2828-2827.

37. M. Buback, G. T. Russell, "Kinetics of Polymerizations", in vol. 4 of: Encyclopedia of Radicals in Chemistry, Biology and Materials, 1st edition, C. Chatgilialoglu, A. Studer, Eds., John Wiley \& Sons Ltd., Chichester, U.K. 2012, pp. 1737-1784.

38. J. Sarnecki, J. Schweer, Macromolecules 1995, 28, 4080-4088. 
39. P. Drawe, M. Buback, Macromol. Theory Simul. 2016, 25, 74-84.

40. P. E. Flory, F. S. Leutner, J. Polym. Sci. 1948, 3, 880-890. 


\title{
For table of contents use only
}

Critically evaluated rate coefficients in radical polymerization -8 . Propagation rate coefficients for vinyl acetate in bulk

\author{
Christopher Barner-Kowollik, Sabine Beuermann, Michael Buback,
}

Robin A. Hutchinson, ${ }^{*}$ Thomas Junkers, Hendrik Kattner, Bart Manders, Anatoly N. Nikitin, Gregory T. Russell, Alex M. van Herk

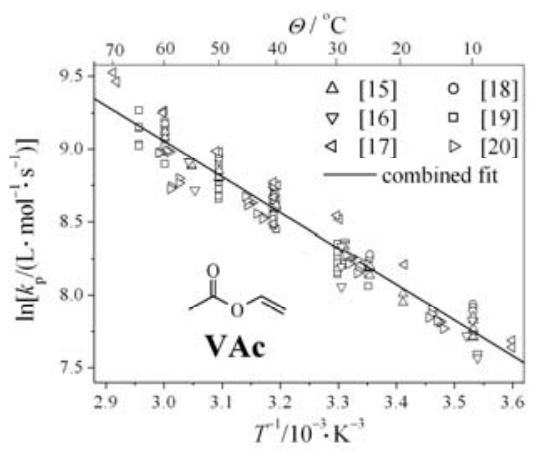

